\title{
Hsp90 and ECM29 Are Important to Maintain the Integrity of Mammalian 26S Proteasome
}

\author{
Jean-Rene Q. Acquah1, Kousuke Haratake1, Randeep Rakwal2, Heiichiro Udono3, \\ Tomoki Chiba ${ }^{*}$ \\ ${ }^{1}$ Graduate School of Life and Environmental Sciences, University of Tsukuba, Ibaraki, Japan \\ ${ }^{2}$ Organization for Educational Initiatives, University of Tsukuba, Ibaraki, Japan \\ ${ }^{3}$ Graduate School of Medicine, Dentistry and Pharmaceutical Sciences, Okayama University, Okayama, Japan \\ Email: "tchiba@biol.tsukuba.ac.jp
}

Received 18 November 2015; accepted 20 December 2015; published 23 December 2015

Copyright (C) 2015 by authors and Scientific Research Publishing Inc.

This work is licensed under the Creative Commons Attribution International License (CC BY).

http://creativecommons.org/licenses/by/4.0/

c) (i) Open Access

\begin{abstract}
The proteasome is a protease complex composed of a core particle (CP) and regulatory particles (RPs) that bind to both ends of the CP. ECM29 is a protein that associates with the proteasome and is involved in the maintenance and regulation of the proteasome assembly. However, ECM29 deficient mice can form functional proteasome. In this paper we sought to identify the mechanisms and/or proteins that help and allow the maintenance of the proteasome activity in the absence of ECM29. We analyzed the proteasome components of ECM29-deficient mice and identified Hsp90 as a protein associated with the proteasome. Furthermore, the inhibition of Hsp90 led to a partial disassembly of the proteasome only in ECM29-deficient cells. Those findings attest to the importance of Hsp90 for the maintenance of the proteasome integrity in the absence of ECM29.
\end{abstract}

\section{Keywords}

\section{Mammalian Proteasome, ECM29, Hsp90, Proteasome Structure}

\section{Introduction}

In eukaryote cells, the 26S proteasome is the main machinery for the degradation of short-lived proteins [1] [2]. The 26S proteasome is the result of the association of the 20S core particule (CP) with a regulatory particle (RP) PA700 (19S) at each of its extremity [3] [4]. The CP, site of the enzymatic activity, is a hollow cylindrical structure formed by four stacked $\alpha$ and $\beta$ rings, arranged in a sequence $\alpha \beta \beta \alpha$. Each of these rings is composed of 7 subunits $(\alpha 1-\alpha 7, \beta 1-\beta 7)$ [5] [6]. The PA700 consists of a base subcomplex and a lid subcomplex. It pos-

${ }^{*}$ Corresponding author.

How to cite this paper: Acquah, J.-R.Q., Haratake, K., Rakwal, R., Udono, H. and Chiba, T. (2015) Hsp90 and ECM29 Are Important to Maintain the Integrity of Mammalian 26S Proteasome. Advances in Biological Chemistry, 5, $255-265$. 
sesses the ability to bind, deubiquitylate and unfold targeted proteins prior to their degradation by the CP [7]-[11]. The CP can also bind to other RPs such as PA200, PA28 $\alpha / \beta$ hetero-heptamer and PA28 $\gamma$ homo-heptamer. This will result in the formation of hybrid proteasomes with specific functions. For example, PA28 $\alpha / \beta$ hetero-heptamer can associate with the CP and is involved in the immune response [12]-[15]. The absence of PA28 $\gamma$ homoheptamer leads to a retardation in cell proliferation [16] [17]. PA200 binding to the proteasome is necessary for a normal spermatogenesis [18]-[21]. Finally ECM29, a conserved HEAT-like repeat protein has been reported to bind to the CP and/or PA700 to maintain the 26S proteasome structure [22]-[25]. In addition to those particles, many other proteins are known to bind and possibly assist the function of the proteasome [26]-[28].

The molecular chaperone Hsp90, one of the most abundant intracellular proteins (1\% - $2 \%$ of total cellular proteins), helps the final maturation of specific client proteins [29]. Its importance has been shown in various cellular processes such as signal transduction, intracellular transport and the response to oxidative stress [30]-[34]. In mammals, Hsp90 $\alpha$ and Hsp90 $\beta$ are the two main isoforms of Hsp90. Hsp90 $\alpha$ is inducible under stress conditions, while Hsp90 $\beta$ is constitutively expressed. Recent studies mainly in yeast also implied that Hsp90 is involved in the maintenance of the 26S structure of the proteasome [35]-[37].

In an attempt to identify new proteasome components in the absence ofECM29, we surprisingly found a relationship between ECM29 and Hsp90 in the maintenance of the proteasome structure. To purify the proteasome, we used a slightly modified affinity method used by Legget et al. [23] in yeast. Here, we applied this method for the first time directly on the liver of WT and ECM29 deficient mice. After purification and analysis by Mass Spectrometry (MS), we identified Hsp90, and found that the amount of Hsp90 $\alpha$ bound to the proteasome was higher in the ECM29 deficient mice. Furthermore, the inhibition of Hsp90 led to a partial dissociation of the proteasome only in ECM29 deficient cells. We also observed that the ECM29 KO cells were more resistant to the treatment by geldanamycin (GA), an Hsp90 inhibitor. Our data clearly show that, Hsp90 associates with the proteasome and helps to maintain the structure of the proteasome in mammalian cells. Moreover, those results suggest a cooperation between Hsp90 and ECM29 to maintain the structure of the proteasome.

\section{Materials and Methods}

\subsection{Knock Out and Transgenic Mice}

Kiaa0368 KO (ECM29 deficient) mice were generated, and its details will be published elsewhere. Transgenic mice that ubiquitously express HTBT-tagged Rpn11 (subunit of PA700 lid) were a gift from Professor Heiichiro Udono (Okayama University). The KO mice with the HTBT-tagged Rpn11 were obtained after several cycles of breeding. The mice genotypes were checked by PCR. The primers used for ECM29 were 5'-CCAGTGTAGCAG GAGTTCTTTCAGG-3', 5'-CATATTTGGTTTTAGATCAGTCCAG-3' and 5'-GATCAGGATGATCTGGACG AAGAG-3'. They amplified a WT band of $2.2 \mathrm{Kbp}$ and a KO band of $600 \mathrm{bp}$. The primers used to check the presence of the HTBT-tagged Rpn11 were5'-TTGTGGATCCCATTCAGAGTGTAA-3' and 5'-TATCGTAGTC ATGATGGTGGTGAT-3'. They amplified a product length of $600 \mathrm{bp}$.

All animal experiments were performed in accordance with the guidelines of the University of Tsukuba's Regulation of Animal Experiments Committee.

\subsection{Preparation of MEFs and Cell Culture}

Mouse embryonic fibroblast (MEF) cells were isolated from 13.5 days post coitus embryos and cultured in Dulbecco's modified Eagle's medium (D-MEM, high glucose) (Wako) supplemented with 10\% fetal bovine serum and $1 \%$ penicillin/streptomycin (Invitrogen) at $37^{\circ} \mathrm{C}, 5 \% \mathrm{CO}_{2}$. MEFs were immortalized by transfecting SV40 large $\mathrm{T}$ antigen (kindly provided from Dr. N. Mizushima [The University of Tokyo, Japan]) using Lipofectamine 2000 (Invitrogen) according to the manufacturer's instruction.

\subsection{Cell Viability Assay}

The MEF cells (WT and ECM29 deficient) were seeded into a 96-well plate at 5000 cells/well and grown for 24 h. The growing medium was replaced by Geldanamycin (GA) (250 nM or $750 \mathrm{nM}$ ) or $0.5 \%$ DMSO (control) in $\mathrm{D}-\mathrm{MEM}$ and the cells were incubated for $48 \mathrm{~h}$. The cell proliferation assay was then conducted according to the manufacturer's instructions (Cell Counting Kit 8, Dojindo). The results are expressed as the relative viability of cells compared to their respective control. 


\subsection{Cells Extract Preparation and Glycerol Density Gradient Centrifugation}

The cells were lysed in $500 \mu \mathrm{l}$ buffer $(50 \mathrm{mM}$ TrisHCl (pH 7.5), $5 \mathrm{mM} \mathrm{MgCl}, 0.5 \%$ NP-40, 2 mM ATP and $1 \mathrm{mM}$ DTT) for 30 min on ice. The lysate was cleared by centrifugation for 30 min at 15,000 g and the supernatant was collected.

$600 \mu \mathrm{l}$ of cell lysates were separated by $10 \%$ - 40\% glycerol density gradient centrifugation (GDGC) for $22 \mathrm{~h}$ at 25,000 rpm at $4^{\circ} \mathrm{C}$ (Beckman Coulter Optima-LE 80k Ultracentrifuge, SW41 rotor). The gradients were fractionated using liquid layer injector fractionator (ADVANTEC) equipped with fraction collector (ATTO).

\subsection{Purification of the Proteasome}

The mouse livers were dissected and homogenized in 5 volumes per liver's weight of buffer A (25 mM TrisHCl (pH 7.5), 10\% Glycerol, 5 mM MgCl, 1 mM PMSF, 5 mM ATP). The lysate was cleared by centrifugation for $20 \mathrm{~min}$ at 10,000 rpm. The supernatant was kept and mixed with $250 \mu$ l Streptavidine-Sepharose's high performance beads (GE healthcare) overnight in cold room. The beads were collected, washed twice in buffer A and mixed with $2 \%(\mathrm{v} / \mathrm{v})$ of AcTEV (Novex) at $30^{\circ} \mathrm{C}$ for $2 \mathrm{~h}$. The mix was centrifuged at 10,000 rpm for $1 \mathrm{~min}$ and the eluates were collected. The elution step was repeated 6 times.

\subsection{Mass Spectrometry Analysis}

The MS analyses were performed as previously described [38]. In brief, the excised spots from the gel were rinsed with $100 \mu \mathrm{l}\left(50 \mathrm{mM}\right.$ ammonium bicarbonate $\left(\mathrm{NH}_{4} \mathrm{HCO}_{3}\right)$ solution in $50 \%$ acetonitrile) and vacuum-dried. For the in-gel digestion, we added $2 \mu \mathrm{l}$ of trypsin solution $\left(10 \mathrm{mM} \mathrm{NH} \mathrm{HCO}_{3}\right.$ and $10 \mathrm{ng} / \mu \mathrm{l}$ of trypsin), and incubated at $37^{\circ} \mathrm{C}$ for $4 \mathrm{~h}$ to overnight. The peptides were extracted with $10 \mu \mathrm{l}(75 \%$ ACN containing $0.025 \%$ trifluoroacetic acid) by ultrasonication. The spot on the MALDI sample plate was loaded with $0.5 \mu \mathrm{l}$ of the matrix ( $\alpha$-Cyano-4-hydroxycinnamic acid (4-CHCA, Shimadzu Biotech, Kyoto, Japan) and $1 \mu$ l of the peptide sample solution. The samples were analyzed by the AXIMA Performance MALDI-TOF-MS (Shimadzu Biotech, Kyoto, Japan) and identified by Peptide Mass Fingerprint (PMF) analysis.

\subsection{Electrophoresis and Western Blot}

Native-PAGE was performed using 3\% - 10\% gradient gels (Wako Pure Chemical Industries) in electrophoresis buffer (180 mM Tris borate ( $\mathrm{pH} \mathrm{8.3).} \mathrm{Protein} \mathrm{samples} \mathrm{were} \mathrm{mixed} \mathrm{with} \mathrm{xylene} \mathrm{cyanol,} \mathrm{run} \mathrm{at} 100 \mathrm{~V}$ until the xylene cyanol dye exited the gel and transferred to PVDF membrane.

Purified proteasome, cleared lysate or GDGC fractions were mixed with $2 \times$ SDS sample buffer, separated by SDS-PAGE and transferred to PVDF membrane.

The membrane was probed with primary antibodies, HRP-conjugated secondary antibodies, and then detected with chemiluminescence reagent (Amersham ECL plus Western Blotting Detection Reagents, GE Healthcare).

\subsection{Antibodies}

Anti-PA28 $\gamma$ monoclonal (BD Transduction Laboratories; 611,180), anti- $\beta 5$ rabbit polyclonal (Abcam; ab3330), anti-Hsp86 rabbit polyclonal (thermo scientific), anti-PA200 rabbit polyclonal (Santa Cruz Biotechnology) and Peroxidase-conjugated anti-rabbit or anti-mouse (Jackson Immuno Research) antibodies were purchased. Anti-ECM29 and anti- $\beta 7$ antibodies were raised from rabbit using the recombinant his-tagged $\beta 7$ and the recombinant his-tagged ECM29 (100 C-terminal amino acid). Anti-PA28 $\alpha$ and anti-Rpt1 antibodies are described previously [39] [40].

\subsection{Proteasome Activity}

$2 \mu \mathrm{l}$ of purified proteasome were mixed with $98 \mu \mathrm{l}$ of buffer $(100 \mathrm{mM}$ TrisHCl (pH 7.5) and $0.01 \mathrm{mM}$ of fluorescent substrate (N-suc-leu-leu-val-tyr-AMC) (Peptide Institute)) and incubated at $37^{\circ} \mathrm{C}$. The fluorescence was read on the 1420 Multilabel counter (Perkin Elmer ex355/em410). For each purified proteasome, the concentration was measured by Bradford assay and the protease activity is as the N-suc-LLVY-AMC hydrolysis/ng/min.

$10 \mu \mathrm{l}$ of GDGC fraction was mixed with $90 \mu \mathrm{l}$ of buffer $(100 \mathrm{mM}$ TrisHCl (pH 8.0), $50 \mathrm{mM} \mathrm{KCl}, 10 \mathrm{mM}$ $\mathrm{MgCl}_{2}, 0.056 \mathrm{mM}$ of fluorescent substrate (N-suc-leu-leu-val-tyr-AMC), $1.12 \mathrm{mM}$ ATP and $39 \mu \mathrm{l}$ of water). The 
fluorescence was read on the 1420 Multilabel counter (Perkin Elmer ex355/em410).

\subsection{Statistical Analysis}

Student's $t$-tests were performed for statistical analyses. Data in all graphs are presented as means \pm S.D.

\section{Results}

\subsection{Purification of Functional Proteasomes from Mice Liver}

The purification method for yeast proteasome by HTBH-tagged Rpn11 was described previously by Leggett et al. [23] [41]. We followed the same method using WT and ECM29 deficient mice with HTBH-tagged Rpn11 (Figure 1(a)). The purified samples (Figure 1(b)) had an SDS-PAGE profile similar to the ones obtained by previous studies [23] [41]. It has been shown that the presence of $100-500 \mathrm{mM}$ of $\mathrm{NaCl}$ is sufficient to dissociate proteins associated to the proteasome [7] [23] [42]. During the purification process on WT mice, we washed the proteasome bound to the streptavidin beads with buffer A containing an increasing concentration of $\mathrm{NaCl}(50,100,150,200,250$ and $300 \mathrm{mM})$. The Eluate of each of the washing step was then analyzed by west-

(a)

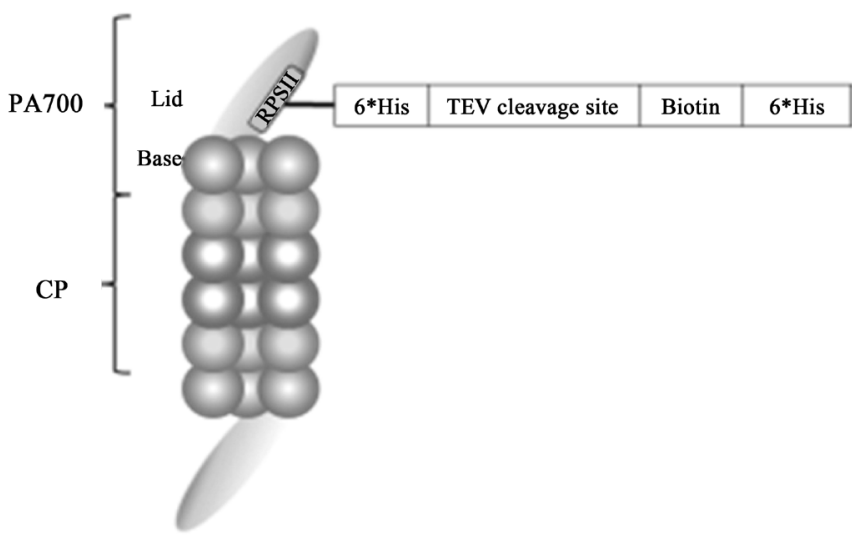

(b)

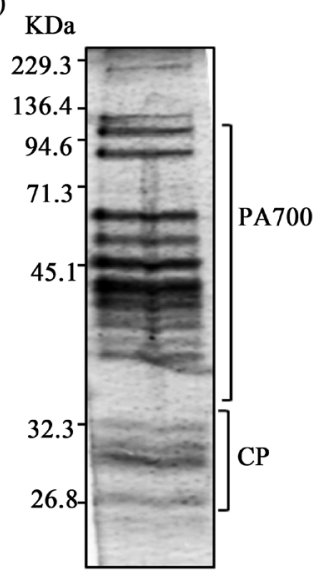

(c)

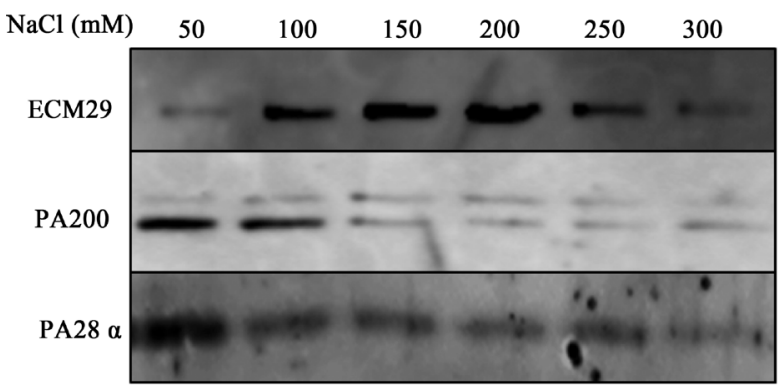

(d)

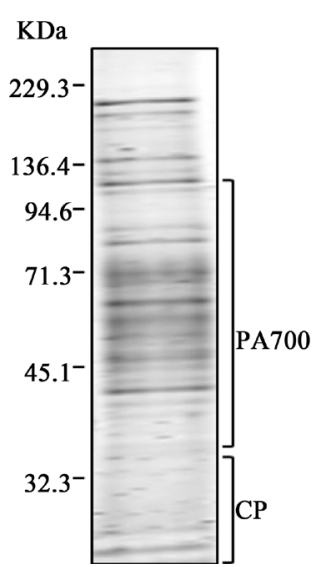

(e)

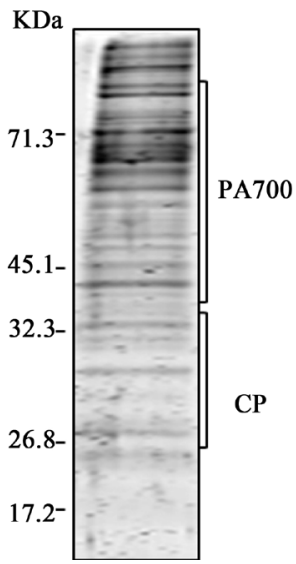

Figure 1. Profile of purified Proteasome. (a) Schematic representation of the proteasome with HTBH tag fused to the C-terminus of Rpn11. The HTBH tag consists of two hexahistidine tags, a TEV cleavage site and a biotin site. (b) The proteasome purified from WT mice liver with buffer A containing $300 \mathrm{mM}$ of $\mathrm{NaCl}$ was separated by SDS-PAGE (10\% gel) and stained by coomassie blue. From $130 \mathrm{KDa}$ to $40 \mathrm{KDa}$ are the proteins that compose PA700. From $35 \mathrm{KDa}$ to $25 \mathrm{KDa}$ are the proteins that compose CP. (c) The proteasome bound to the streptavidin beads was washed with buffer A containing 50 , 100, 150, 200, 250 and $300 \mathrm{mM}$ of $\mathrm{NaCl}$. The eluates were analyzed by WB for the respective proteins. (d) (e) The proteasome was purified as in A with Buffer A $(0 \mathrm{mM} \mathrm{NaCl})$. The samples were separated by SDS-PAGE and stained by Sypro-Ruby (D. 7.5\% gel, E. 12\% gel). 
ern blot (WB) of proteasome associated proteins (ECM29, PA200, PA28 $\alpha$ ) (Figure 1(c)). We noticed that lower concentration of $\mathrm{NaCl}$ (from $50 \mathrm{mM}$ ) also causes the dissociation of these proteins associated to the proteasome (Figure 1(c)). To avoid losing proteins associated to the proteasome, we excluded the $\mathrm{NaCl}$ and the surfactant from the purification buffer in following analyses. The SDS-PAGE profile of the proteasome purified by the modified buffer contained more bands (Figure 1(d) and Figure 1(e)), showing that more proteins were co-purified with the proteasome.

To assert that we purified functional proteasomes, we first checked the peptidase activity of the purified samples from WT and ECM29 deficient mice. A significant protease activity was detected for the purified samples compared to the control (mice with no tag) (Figure 2(a)). This result was consistent with findings of a previous study showing that ECM29 inhibits the peptidase activity of the proteasome [43]. It also proved that there is no unspecific binding of the proteasome to the streptavidin beads.

Finally, we confirmed by WB the presence of the CP subunit, the PA700, PA200, PA28 $\alpha$ and PA28 $\gamma$. According to the results, our method retained the CP, the PA700 and other known associated proteins such as PA200, PA28 $\alpha$, PA28 $\gamma$ and ECM29 (Figure 2(b)). The WB of the control also showed that the purification of these proteasome components is specific. Taken together, these data confirmed that our modified method could purify an active proteasome including hybrid proteasomes directly from the liver.

\subsection{More Hsp90 Bind to the Proteasome in the Absence of ECM29}

Next, we analyzed the components of the purified proteasome by MS and identified Hsp90 $\alpha$ and Hsp90 $\beta$ as candidate proteins. The presence of Hsp90 $\alpha$ and the specificity of its association with the proteasome was further confirmed by WB of the purified samples from WT, ECM29 deficient and control mice (Figure 3(a)). Interestingly, we found that the quantity of Hsp90 $\alpha$ binding to the proteasome was higher in the case of the ECM29 deficient mice (Figure 3(a) and Figure 3(b)). Hsp90 is a stress-induced chaperone protein in mammalian cells. The variation observed might be a result of the increase of the total cytosolic Hsp90 in ECM29 KO condition. To eliminate this possibility, we checked the amount of Hsp90 in the lysate of liver from WT and ECM29 deficient mice (Figure 3(c) and Figure 3(d)). No noticeable variation was observed. Taken together our data imply a link between Hsp90 function and the absence of ECM29.

(a)

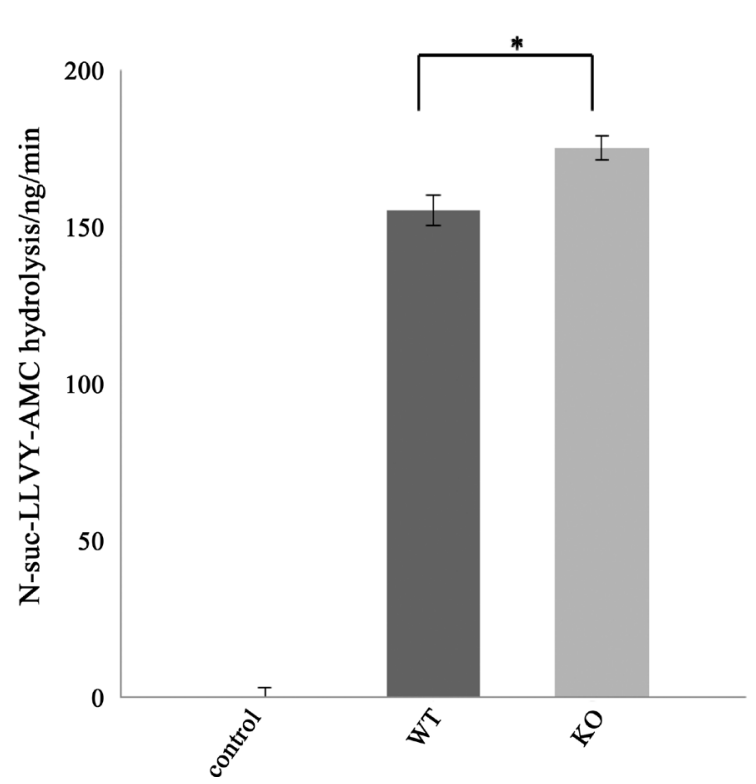

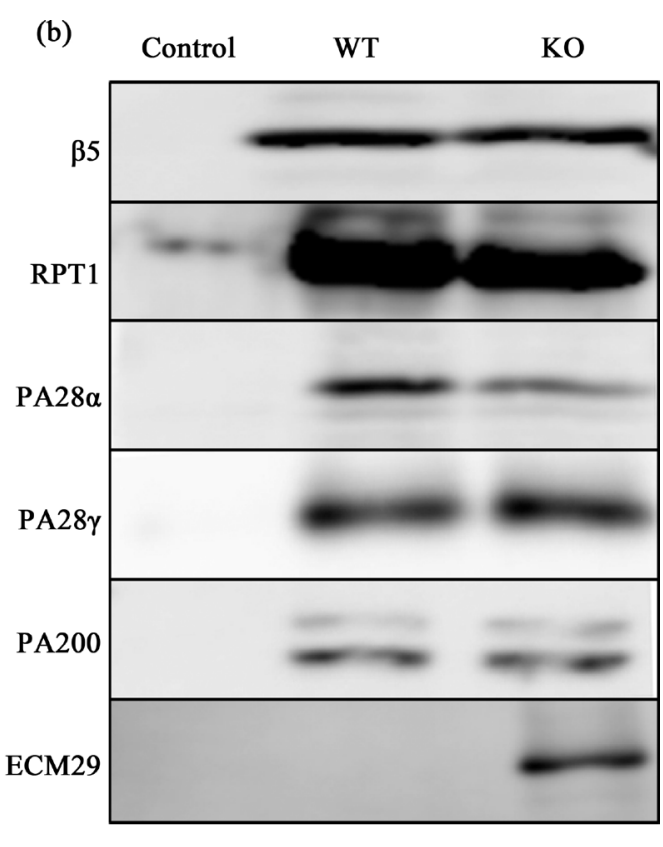

Figure 2. The purified proteasomes contain the 26S subunit and the well known proteasome associated proteins. (a) The purified samples from WT, ECM29 deficient and control (without the tag) liver were incubated with fluorescent substrate for 30 min. The results represent the mean \pm S.D $(n=3) . *{ }^{*} p 0.005$. The protease activity is expressed by N-suc-LLVY-AMC hydrolysis/ng/min. (b) Purified samples from WT, Ecm29 KO, and control mice were immunoblotted with indicated antibodies. $\beta 5$ (CP subunit), RPT1 (PA700 subunit), PA28 $\alpha$, PA28 $\gamma$, PA200, ECM29 (proteasome associated proteins). 
(a)

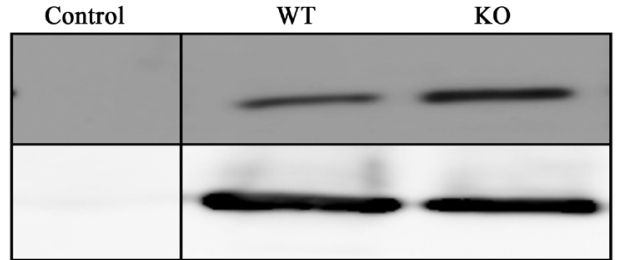

(b)

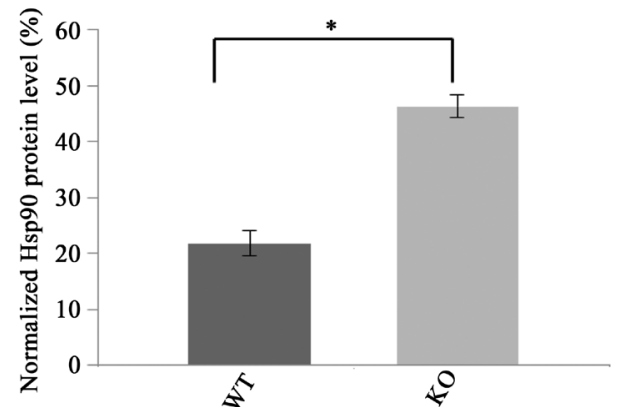

(c)

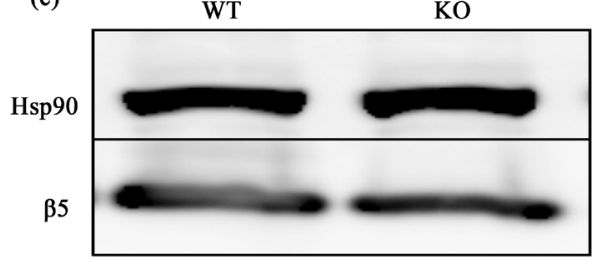

(d)

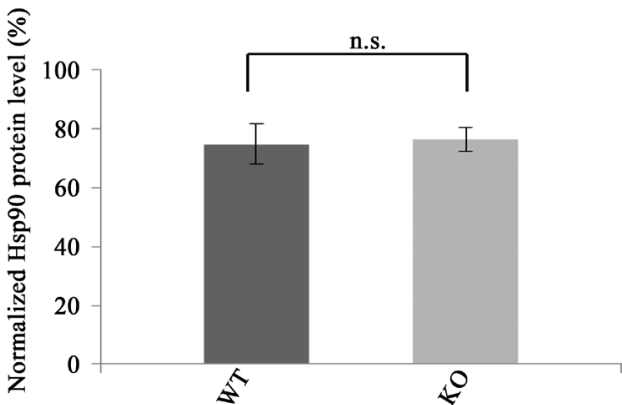

Figure 3. Hsp90 binds more abundantly to the proteasome in the absence of ECM29. (a) The purified samples from WT, ECM29 deficient and control mice were analyzed by WB against Hsp90 and $\beta 5$. (b) The intensity of Hsp90 signal from A was measured by ImageJ and normalized with the signal intensity of $\beta 5$, subunit of CP. (c) Liver lysate were analyzed by WB against Hsp90 and $\beta 5$ from WT and ECM29. (d) The intensity of Hsp90 signal from (c) was measured by ImageJ and normalized with the signal intensity of $\beta 5$. The results represent the mean \pm S.D of 3 independent experiments. ${ }^{*} p<0.005$. n.s. not significant.

\subsection{Hsp90 Helps to Maintain the Proteasome Integrity}

As ECM29 has been reported to stabilize the 26S proteasome complex in yeast, we focused on the proteasome structure. To elucidate the functional link between Hsp90 and ECM29 on the structure of the proteasome, we ran a glycerol density gradient centrifugation experiment (GDGC) with WT and ECM29 deficient cell lysates following treatment with Geldanamycin (GA), an inhibitor of Hsp90. We then checked the proteasome activity of each fraction. GA treatment induced no differences for the WT cells (Figure 4(a)), but the peak of the proteasome activity shifted from the $20^{\text {th }}$ fraction to the lighter $19^{\text {th }}$ fraction in ECM29 deficient cells (Figure 4(b)). This shift suggests a partial disassembly of the proteasome, and these results imply that the presence of ECM29 stabilizes the proteasome structure when Hsp90 is absent. In ECM29 deficient cells, the shift correlated with the decrease of Hsp90 $\alpha$ present in the fraction of maximum activity upon GA treatment (Figure 4(b)). However, no noticeable decrease of Hsp90 $\alpha$ was observed for the WT lysate (Figure 4(a)).This may suggest a preferential binding of Hsp90 to the proteasome in the absence of ECM29.

To confirm the direct effect of Hsp90 on the proteasome and avoid any interference by the components of the lysates, we treated the purified proteasome with GA. Native-PAGE followed by WB showed that GA treatment of the proteasome lacking ECM29 led to an increase in intermediate varieties of proteasome and lower molecular weight sub-complex containing RPT1, a subunit of PA700 (Figure 5(a) and Figure 5(d)). Likewise, in the proteasome lacking ECM29, the GA treatment led also to the increase in intermediate varieties of proteasome containing $\beta 5$, a subunit of the CP (Figure 5(b) and Figure 5(e)). Western blots against PA200, PA28 $\alpha$ or PA28 $\gamma$ did not show any differences, suggesting that Hsp90 is not involved in the association or dissociation of these RPs even in the absence of ECM29 (Figure 5(c), Figure 5(f) and data not shown). Taken together, these results suggest that in the absence of ECM29, the inhibition of Hsp90 causes a dissociation of the PA700 from the CP proteasome.

\subsection{ECM29 Deficient Cells are More Resistant to GA Treatment}

Finally we checked the impact of the GA treatment on the survival of WT and ECM29-deficient cells. We present the cell viability by the percentage of viable cells compared to the control cells (WT and ECM29 deficient cells treated with DMSO only) to account for a possible difference of growth rates. Surprisingly, we found that ECM29 deficient cells were more resistant to the GA treatment (Figure 6). 

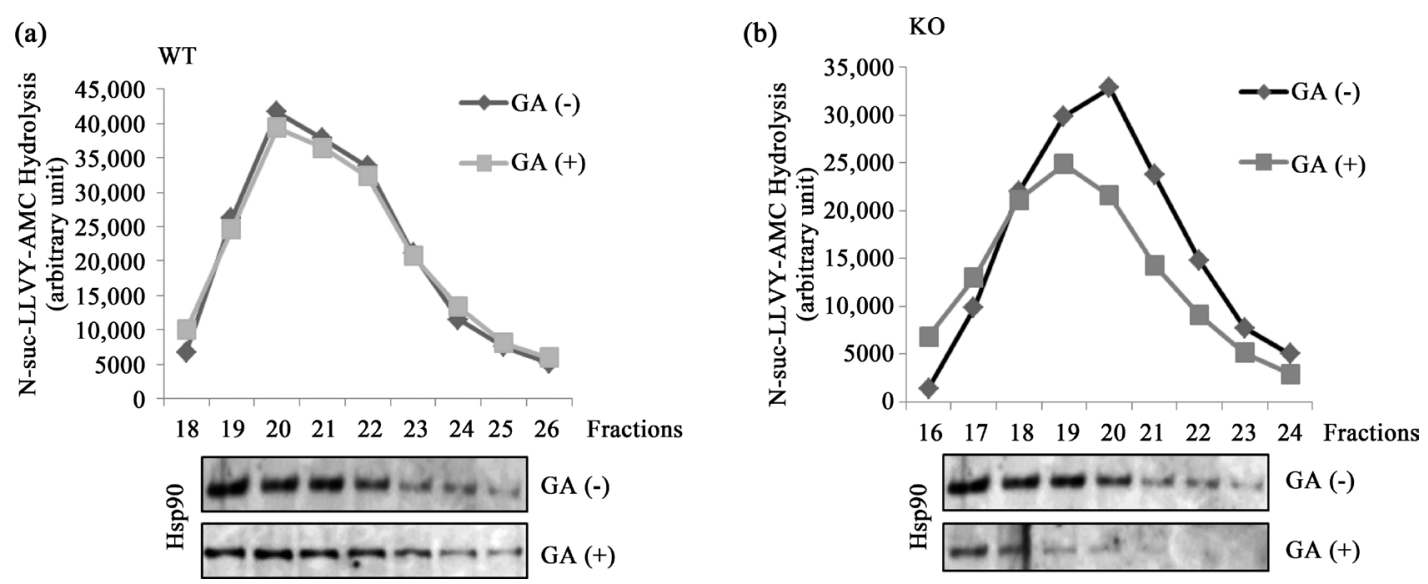

Figure 4. Inhibition of Hsp90 leads to the disassembly of the proteasome in ECM29 deficient cells. (a) WT cell lysates treated without GA $(-)$ or with GA $(+)(60 \mu \mathrm{M})$ were subjected to GDGC. The proteasome activities (top) and WB of Hsp90 (bottom) in the indicated fractions are shown. (b) ECM29 deficient cell lysates were analyzed as in (a).

(a)

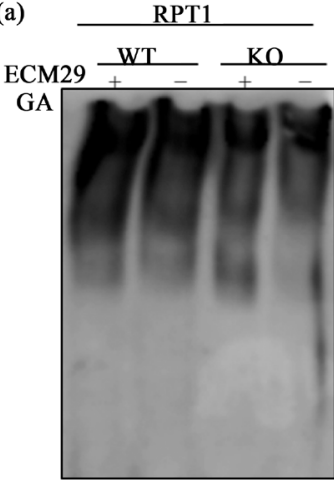

(d)

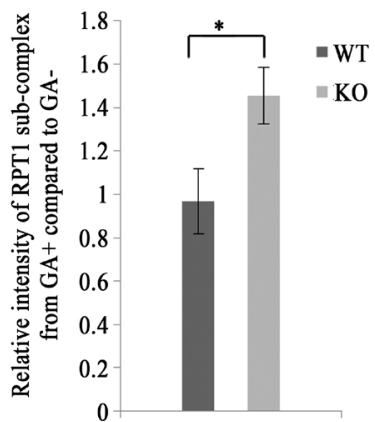

(b)

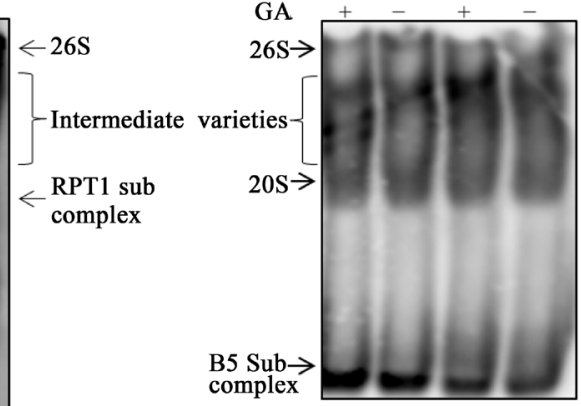

complex

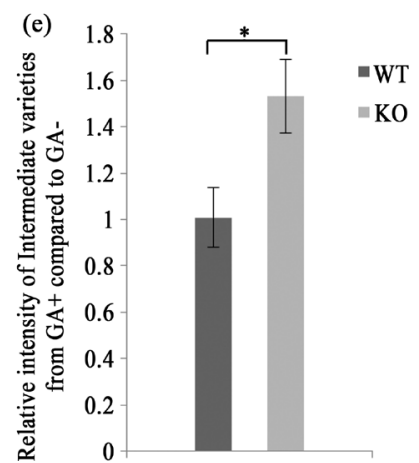

(c)
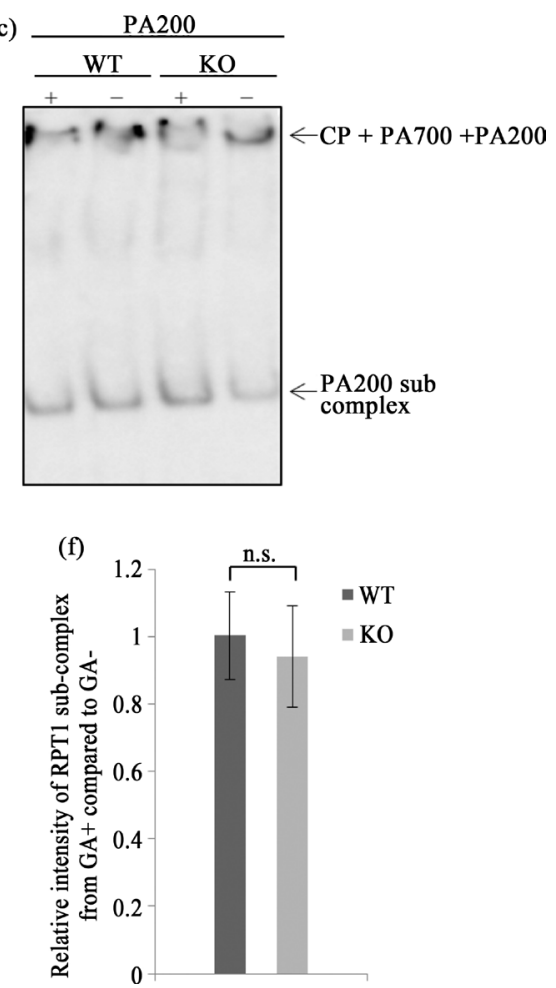

Figure 5. GA treatment of purified proteasome leads to a disassembly of PA700 from the CP. (a)-(c) The purified proteasome from WT mice and ECM29 deficient mice were treated with GA $(150 \mu \mathrm{M})$, separated by a native-PAGE and subjected to WB against the indicated proteins (RPT1, $\beta 5$ and PA200). (d)-(f) The intensity of the RPT1 sub complex (a), the intermediate forms (b) and PA200 sub complex (c) were measured (WT and KO) with or without GA treatment and the relative intensity of GA+ compared to GA- was calculated. The results are shown in (d), (e), and (f), respectively. The results represent the mean \pm S.D. ${ }^{*} p<0.005$. n.s. not significant.

\section{Discussion}

The proteasome is involved in numerous cellular processes and its dysfunction leads to serious diseases. A major challenge to understand this complex is to identify the proteins that associate with the proteasome and to elucidate the effect of those proteins on the proteasome. To achieve this goal we based our strategy on the purification of the proteasome by a very efficient and gentle technique using an HTBH-tag. For the first time, we ap- 


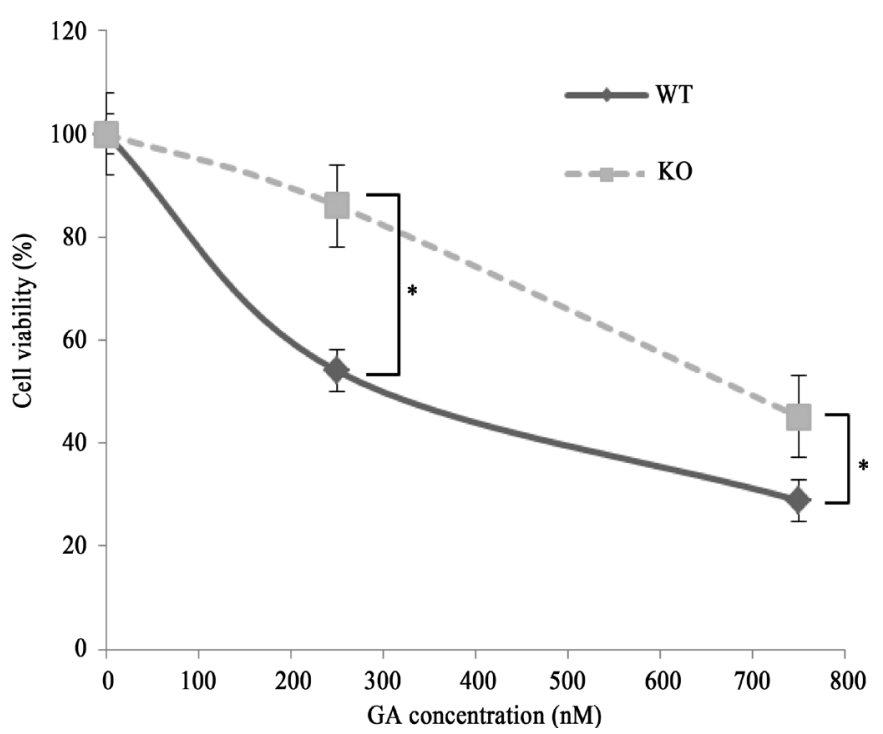

Figure 6. ECM29 deficient cells are more resistant to GA treatment. WT and ECM29 deficient cells were treated with GA ( $250 \mathrm{nM}$ or $750 \mathrm{nM}$ ) for $48 \mathrm{~h}$. The cell viability was then measured by WST8 assay and presented as the relative viability to their respective untreated control $\left(0.5 \%\right.$ DMSO). The results represent the mean \pm S.D $(n=5){ }^{*} p<0.005$.

plied this method directly on WT and ECM29 deficient mice liver and identified Hsp90 by MS. In mammalian cells, only one study discussed the involvement of Hsp90 in the proteasome assembly in vitro [37]. In yeast, previous studies [35] [36] revealed an interaction between the proteasome and Hsp90. Imai et al. [35] reported that Hsp90 plays a role in the maintenance of the proteasome structure, since the proteasome of the yeast Hsp90 mutant was disassembled at non-permissive temperature. They also reported that the GA-treatment of wild-type yeast proteasome didn't lead to the disassembly of the 26S structure.

In the present study, we confirm by MS and WB that Hsp90 is associated with the proteasome in mammalian cells. We find that the amount of Hsp90 associates to the proteasome is higher in the absence of ECM29. We also shed more light on the function of Hsp90 and ECM29 which helps to maintain the 26S structure of the proteasome. Indeed, we reveal a link between the Hsp90 and ECM29 functions since GA treatment led to the partial dissociation of the proteasome only in the absence of ECM29. Our data suggest that ECM29 stabilizes the proteasome structure after Hsp90 has completed its function. This explains why the inhibition of Hsp90 doesn't lead to the dissociation of the proteasome in the WT lines. Accordingly, in the absence of ECM29, the inhibition of Hsp90 leads to the disassembly of the 26S proteasome.

Curiously, in the GDGC experiment, the GA treatment of the WT lysates didn't lead to a marked shift of Hsp90 around the fraction of maximum proteasome activity as observed in the ECM29 deficient cell lysates (Figure 4(a), Figure 4(b)). As explained by Schneider et al. [44], Hsp90 can still remain bound to its protein client while inhibited. In this case, the decrease of Hsp90 observed in the ECM29 deficient cells (Figure 4(b)) would be the consequence of the dissociation of PA700 from CP and couldn't be observed in WT cells since there was no dissociation. Also, we detected Hsp90 in the heaviest fractions of WT cells but not of ECM29 deficient cells (Figure 4(a) and Figure 4(b)). Since Hsp90 stabilizes the structure of the proteasome in the absence of ECM29, Hsp90 would be mostly bound to the proteasome. In the WT cells, Hsp90 is free from this role by the presence of ECM29 and bind to other client proteins present in the heaviest fractions. This may suggest a preferential binding of Hsp90 to the proteasome in the absence of ECM29.

GA treatment of cells causes a disruption of Hsp90 protein clients and an increase in reactive oxygen species (ROS) level leading to the cell death [45]. Previous studies imply that an increase in CP and hybrid proteasomes helps the cells to eliminate the ROS more efficiently [46]-[48]. We have shown that, upon GA treatment, a partial dissociation of the 26S occurs in the absence of ECM29. This means that in ECM29 deficient cells, the formation of CP and hybrid proteasomes is facilitated, ensuring a better elimination of ROS and thus a better viability (Figure 6).

Taken together, our data provide a better understanding of how the structure of the proteasome is maintained and show a functional link between ECM29 and Hsp90 on the proteasome structure. However, the precise me- 
chanism of this relation under normal and stress conditions must be thoroughly investigated in the future.

\section{Acknowledgements}

We thank the members of the Chiba Laboratory for engaging with us in helpful discussion. This work was supported by Grants-in-Aid from the Ministry of Education, Culture, Sports, Science, and Technology (MEXT) of Japan (T.C.). J.Q.A was supported by the MEXT scholarship for foreign student.

\section{Conflict of Interest}

The authors have declared that no conflict of interest exists.

\section{References}

[1] Rock, K.L., Gramm, C., Rothstein, L., Clark, K., Stein, R., Dick, L., Hwang, D. and Goldberg, A.L. (1994) Inhibitors of the Proteasome Block the Degradation of Most Cell Proteins and the Generation of Peptides Presented on MHC Class I Molecules. Cell, 78, 761-771. http://dx.doi.org/10.1016/S0092-8674(94)90462-6

[2] Lee, D.H. and Goldberg, A.L. (1998) Proteasome Inhibitors: Valuable New Tools for Cell Biologists. Trends in Cell Biology, 8, 397-403. http://dx.doi.org/10.1016/S0962-8924(98)01346-4

[3] Hoffman, L., Pratt, G. and Rechsteiner, M. (1992) Multiple Forms of the 20S Multicatalytic and the 26 S Ubiquitin/ ATP-Dependent Proteases from Rabbit Reticulocyte Lysate. The Journal of Biological Chemistry, 267, 22362-22368.

[4] Da Fonseca, P.C.A. and Morris, E.P. (2008) Structure of the Human 26S Proteasome: Subunit Radial Displacements Open the Gate into the Proteolytic Core. The Journal of Biological Chemistry, 283, 23305-23314. http://dx.doi.org/10.1074/jbc.M802716200

[5] Löwe, J., Stock, D., Jap, B., Zwickl, P., Baumeister, W. and Huber, R. (1995) Crystal Structure of the 20S Proteasome from the Archaeon T. Acidophilum at 3.4 A Resolution. Science, 268, 533-539. http://dx.doi.org/10.1126/science.7725097

[6] Groll, M., Ditzel, L., Löwe, J., Stock, D., Bochtler, M., Bartunik, H.D. and Huber R. (1997) Structure of 20S Proteasome from Yeast at $2.4 \AA$ Resolution. Nature, 386, 463-471. http://dx.doi.org/10.1038/386463a0

[7] Glickman, M.H., Rubin, D.M., Fried, V.A. and Finley, D. (1998) The Regulatory Particle of the Saccharomyces cerevisiae Proteasome. Molecular and Cellular Biology, 18, 3149-3162. http://dx.doi.org/10.1128/MCB.18.6.3149

[8] Glickman, M.H., Rubin, D.M., Coux, O., Wefes, I., Pfeifer, G., Cjeka, Z., Baumeister, W., Fried, V.A. and Finley, D. (1998) A Subcomplex of the Proteasome Regulatory Particle Required for Ubiquitin-Conjugate Degradation and Related to the COP9-Signalosome and eIF3. Cell, 94, 615-623. http://dx.doi.org/10.1016/S0092-8674(00)81603-7

[9] Larsen, C.N. and Finley, D. (1997) Protein Translocation Channels in the Proteasome and Other Proteases. Cell, 91, 431-434. http://dx.doi.org/10.1016/S0092-8674(00)80427-4

[10] Baumeister, W., Walz, J., Zuhl, F. and Seemuller, E. (1998) The Proteasome: Paradigm of a Self-Compartmentalizing Protease. Cell, 92, 367-380. http://dx.doi.org/10.1016/S0092-8674(00)80929-0

[11] Pickart, C. (1997) Targeting of Substrates to the 26S Proteasome. The FASEB Journal, 11, 1055-1066.

[12] Ahn, K., Erlander, M., Leturcq, D., Peterson, P.A., Früh, K. and Yang, Y. (1996) In Vivo Characterization of the Proteasome Regulator PA28. The Journal of Biological Chemistry, 271, 18237-18242. http://dx.doi.org/10.1074/jbc.271.30.18237

[13] Kuehn, L. and Dahlmann, B. (1997) Structural and Functional Properties of Proteasome Activator PA28. Molecular Biology Reports, 24, 89-93. http://dx.doi.org/10.1023/A:1006897801858

[14] Preckel, T., Fung-Leung, W.P., Cai, Z., Vitiello, A., Salter-Cid, L., Winqvist, O., Wolfe, T.G., Von Herrath, M., Angulo, A., Ghazal, P., Lee, J.D., Fourie, A.M., Wu, Y., Pang, J., Ngo, K., Peterson, P.A., Früh, K. and Yang, Y. (1999) Impaired Immunoproteasome Assembly and Immune Responses in PA28 ${ }^{-/-}$Mice. Science, 286, 2162-2165. http://dx.doi.org/10.1126/science.286.5447.2162

[15] Cascio, P., Call, M., Petre, B.M., Walz, T. and Goldberg, A.L. (2002) Properties of the Hybrid Form of the 26S Proteasome Containing both 19S and PA28 Complexes. The EMBO Journal, 21, 2636-2645. http://dx.doi.org/10.1093/emboj/21.11.2636

[16] Zhang, Z. and Zhang, R. (2008) Proteasome Activator PA28 $\gamma$ Regulates p53 by Enhancing Its MDM2-Mediated Degradation. The EMBO Journal, 27, 852-864. http://dx.doi.org/10.1038/emboj.2008.25

[17] Murata, S., Kawahara, H., Tohma, S., Yamamoto, K., Kasahara, M., Nabeshima, Y.I., Tanaka, K. and Chiba, T. (1999) Growth Retardation in Mice Lacking the Proteasome Activator PA28 $\gamma$. The Journal of Biological Chemistry, 274, 
38211-38215. http://dx.doi.org/10.1074/jbc.274.53.38211

[18] Ortega, J., Heymann, J.B., Kajava, A.V., Ustrell, V., Rechsteiner, M. and Steven, A.C. (2005) The Axial Channel of the 20S Proteasome Opens upon Binding of the PA200 Activator. Journal of Molecular Biology, 346, 1221-1227. http://dx.doi.org/10.1016/j.jmb.2004.12.049

[19] Iwanczyk, J., Sadre-Bazzaz, K., Ferrell, K., Kondrashkina, E., Formosa, T., Hill, C.P. and Ortega1, J. (2006) Structure of the Blm10-20S Proteasome Complex by Cryo-Electron Microscopy, Insights into the Mechanism of Activation of Mature Yeast Proteasomes. Journal of Molecular Biology, 363, 648-659. http://dx.doi.org/10.1016/j.jmb.2006.08.010

[20] Blickwedehl, J., Olejniczak, S., Cummings, R., Sarvaiya, N., Mantilla, A., Chanan-Khan, A., Pandita, T.K., Schmidt, M., Thompson, C.B. and Bangia, N. (2012) The Proteasome Activator PA200 Regulates Tumor Cell Responsiveness to Glutamine and Resistance to Ionizing Radiation. Molecular Cancer Research, 10, 937-944. http://dx.doi.org/10.1158/1541-7786.MCR-11-0493-T

[21] Khor, B., Bredemeyer, A.L., Huang, C.Y., Turnbull, I.R., Evans, R., Maggi, L.B., White, J.M., Walker, L.M., Carnes, K., Hess, R.A. and Sleckman, B.P. (2006) Proteasome Activator PA200 Is Required for Normal Spermatogenesis. Molecular and Cellular Biology, 26, 2999-3007. http://dx.doi.org/10.1128/MCB.26.8.2999-3007.2006

[22] Gorbea, C., Goellner, G.M., Teter, K., Holmes, R.K. and Rechsteiner, M. (2004) Characterization of Mammalian Ecm29, a 26S Proteasome-Associated Protein That Localizes to the Nucleus and Membrane Vesicles. The Journal of Biological Chemistry, 279, 54849-54861. http://dx.doi.org/10.1074/jbc.M410444200

[23] Leggett, D.S., Hanna, J., Borodovsky, A., Crosas, B., Schmidt, M., Baker, R.T., Walz, T., Ploegh, H. and Finley, D. (2002) Multiple Associated Proteins Regulate Proteasome Structure and Function. Molecular Cell, 10, 495-507. http://dx.doi.org/10.1016/S1097-2765(02)00638-X

[24] Lehmann, A., Niewienda, A., Jechow, K., Janek, K. and Enenkel, C. (2010) Ecm29 Fulfils Quality Control Functions in Proteasome Assembly. Molecular Cell, 38, 879-888. http://dx.doi.org/10.1016/j.molcel.2010.06.016

[25] Kajavaa, A.V., Gorbeab, C., Ortegac, J., Rechsteinerb, M. and Steven, A.C. (2004) New HEAT-Like Repeat Motifs in Proteins Regulating Proteasome Structure and Function. Journal of Structural Biology, 146, 425-430. http://dx.doi.org/10.1016/j.jsb.2004.01.013

[26] Elsasser, S., Chandler-Militello, D., Müller, B., Hanna, J. and Finley, D. (2004) Rad23 and Rpn10 Serve as Alternative Ubiquitin Receptors for the Proteasome. The Journal of Biological Chemistry, 279, 26817-26822. http://dx.doi.org/10.1074/jbc.M404020200

[27] Schmidt, M., Hanna, J., Elsasser, S. and Finley, D. (2005) Proteasome-Associated Proteins: Regulation of a Proteolytic Machine. The Journal of Biological Chemistry, 386, 725-737. http://dx.doi.org/10.1515/BC.2005.085

[28] Guerrero, C., Tagwerker, C., Kaiser, P. and Huang, L. (2006) An Integrated Mass Spectrometry-Based Proteomic Approach: Quantitative Analysis of Tandem Affinity-Purified in Vivo Cross-Linked Protein Complexes (QTAX) to Decipher the 26S Proteasome-Interacting Network. Molecular and Cellular Proteomics, 5, 366-378. http://dx.doi.org/10.1074/mcp.M500303-MCP200

[29] Taipale, M., Jarosz, D.F. and Lindquist, S. (2010) Hsp90 at the Hub of Protein Homeostasis: Emerging Mechanistic Insights. Nature Reviews Molecular Cell Biology, 11, 515-528. http://dx.doi.org/10.1038/nrm2918

[30] Nathan, D.F., Vos, M.H. and Lindquist, S. (1997) In Vivo Functions of the Saccharomyces cerevisiae Hsp90 Chaperone. Proceedings of the National Academy of Sciences of the United States of America, 94, 12949-12956. http://dx.doi.org/10.1073/pnas.94.24.12949

[31] Zhao, R., Davey, M., Hsu, Y.C., Kaplanek, P., Tong, A., Parsons, A.B., Krogan, N., Cagney, G., Mai, D., Greenblatt, J., Boone, C., Emili, A. and Houry, W.A. (2005) Navigating the Chaperone Network: An Integrative Map of Physical and Genetic Interactions Mediated by the Hsp90 Chaperone. Cell, 120, 715-727. http://dx.doi.org/10.1016/j.cell.2004.12.024

[32] Picard, D. (2002) Heat-Shock Protein 90, a Chaperone for Folding and Regulation. Cellular and Molecular Life Sciences, 59, 1640-1648. http://dx.doi.org/10.1007/PL00012491

[33] Smith, D.F. (1993) Dynamics of Heat-Shock Protein 90-Progesterone Receptor Binding and the Disactivation Loop Model for Steroid Receptor Complexes. Molecular Endocrinology, 7, 1418-1429. http://www.ncbi.nlm.nih.gov/pubmed/7906860

[34] Pratt, W.B., Morishima, Y., Peng, H.M. and Osawa, Y. (2010) Proposal for a Role of the Hsp90/Hsp70-Based Chaperone Machinery in Making Triage Decisions When Proteins Undergo Oxidative and Toxic Damage. Experimental Biology and Medicine, 235, 278-289. http://dx.doi.org/10.1258/ebm.2009.009250

[35] Imai, J., Maruya, M., Yashiroda, H., Yahara, I. and Tanaka, K. (2003) The Molecular Chaperone Hsp90 Plays a Role in the Assembly and Maintenance of the 26S Proteasome. The EMBO Journal, 22, 3557-3567. http://dx.doi.org/10.1093/emboj/cdg349

[36] Verma, R., Chen, S., Feldman, R., Schieltz, D., Yates, J., Dohmen, J. and Deshaies, R.J. (2000) Proteasomal Proteo- 
mics: Identification of Nucleotide-Sensitive Proteasome-Interacting Proteins by Mass Spectrometric Analysis of Affinity-Purified Proteasomes. Molecular Biology of the Cell, 11, 3425-3439. http://dx.doi.org/10.1091/mbc.11.10.3425

[37] Yamano, T., Mizukami, S., Murata, S., Chiba, T., Tanaka, K. and Udono, H. (2008) Hsp90-Mediated Assembly of the 26S Proteasome Is Involved in Major Histocompatibility Complex Class I Antigen Processing. The Journal of Biological Chemistry, 283, 28060-28065. http://dx.doi.org/10.1074/jbc.M803077200

[38] Hori, M., Nakamachi, T., Rakwal, R., Shibato, J., Ogawa, T., Aiuchi, T., Tsuruyama, T., Tamaki, K. and Shioda, S. (2012) Transcriptomics and Proteomics Analyses of the PACAP38 Influenced Ischemic Brain in Permanent Middle Cerebral Artery Occlusion Model Mice. Journal of Neuroinflammation, 9, 256-274.

http://www.jneuroinflammation.com/content/pdf/1742-2094-9-256.pdf http://dx.doi.org/10.1186/1742-2094-9-256

[39] Tanahashi, N., Yokota, K., Ahn, J.Y., Chung, C.H., Fujiwara, T., Takahashi, E., DeMartino G.N., Slaughter, C.A., Toyonaga, T., Yamamura, K., Shimbara, N. and Tanaka, K. (1997) Molecular Properties of the Proteasome Activator PA28 Family Proteins and Gamma-Interferon Regulation. Genes to Cells, 2, 195-211. http://onlinelibrary.wiley.com/doi/10.1046/j.1365-2443.1997.d01-308.x/epdf http://dx.doi.org/10.1046/j.1365-2443.1997.d01-308.x

[40] Tanahashi, N., Suzuki, M., Fujiwara, T., Takahashi, E., Shimbara, N., Chung, C.H. and Tanaka, K. (1998) Chromosomal Localization and Immunological Analysis of a Family of Human 26S Proteasomal ATPases. Biochemical and Biophysical Research Communications, 243, 229-232. http://dx.doi.org/10.1006/bbrc.1997.7892

[41] Leggett, D.S., Glickman, M.H. and Finley, D. (2005) Purification of Proteasomes, Proteasome Subcomplexes, and Proteasome-Associated Proteins from Budding Yeast. Methods in Molecular Biology, 301, 57-70. http://dx.doi.org/10.1385/1-59259-895-1:057

[42] Besche, H.C., Haas, W., Gygi, S.P. and Goldberg, A.L. (2009) Isolation of Mammalian 26S Proteasomes and p97/VCP Complexes Using the Ubiquitin-Like Domain from HHR23B Reveals Novel Proteasome-Associated Proteins. Biochemistry, 48, 2538-2549. http://dx.doi.org/10.1021/bi802198q

[43] De La Mota-Peynado, Lee, S.Y.C., Pierce, B.M., Wani, P., Singh, C.R. and Roelofs, J. (2013) The Proteasome-Associated Protein Ecm29 Inhibits Proteasomal ATPase Activity and in Vivo Protein Degradation by the Proteasome. The Journal of Biological Chemistry, 288, 29467-29481. http://dx.doi.org/10.1074/jbc.M113.491662

[44] Schneider, C., Sepp-Lorenzino, L., Nimmesgern, E., Ouerfelli, O., Danishefsky, S., Rosen, N. and Hartl, F.U. (1996) Pharmacologic Shifting of a Balance between Protein Refolding and Degradation Mediated by Hsp90. Proceedings of the National Academy of Sciences of the United States of America, 93, 14536-14541. http://dx.doi.org/10.1073/pnas.93.25.14536

[45] Aparajita, D., and Arthur, I.C. (2006) Geldanamycin, an Inhibitor of Hsp90, Potentiates Cytochrome P4502E1-Mediated Toxicity in HepG2 Cells. Journal of Pharmacology and Experimental Therapeutics, 317, 1391-1399. http://dx.doi.org/10.1124/jpet.106.101808

[46] Pickering, A.M., Koop, A.L., Teoh, C.Y., Ermak, G., Grune T. and Davies K. J. (2010) The Immunoproteasome, the 20S Proteasome, and the PA28 $\alpha \beta$ Proteasome Regulator Are Oxidative-Stress-Adaptive Proteolytic Complexes. Biochemical Journal, 432, 585-594. http://dx.doi.org/10.1042/BJ20100878

[47] Seifert, U., Bialy, L.P., Ebstein, F., Bech-Otschir, D., Voigt, A., Schröter, F., Prozorovski, T., Lange, N., Steffen, J., Rieger, M., Kuckelkorn, U., Aktas, O., Kloetzel, P.M. and Krüger, E. (2010) Immunoproteasomes Preserve Protein Homeostasis upon Interferon-Induced Oxidative Stress. Cell, 142, 613-624. http://dx.doi.org/10.1016/j.cell.2010.07.036

[48] Charity, T.A., Robyn, M.K., Xiaorong, W. and Lan, H. (2011) Oxidative Stress-Mediated Regulation of Proteasome Complexes. Molecular and Cellular Proteomics, 10, Article ID: 006924. 